\title{
The mechanism of sperm-egg interaction and the involvement of IZUMO1 in fusion
}

\author{
Naokazu Inoue, Masahito Ikawa and Masaru Okabe
}

An average human ejaculate contains over 100 million sperm, but only a few succeed in accomplishing the journey to an egg by migration through the female reproductive tract. Among these few sperm, only one participates in fertilization. There might be an ingenious molecular mechanism to ensure that the very best sperm fertilize an egg. However, recent gene disruption experiments in mice have revealed that many factors previously described as important for fertilization are largely dispensable. One could argue that the fertilization mechanism is made robust against gene disruptions. However, this is not likely, as there are already six different gene-disrupted mouse lines (Calmegin, Adam1a, Adam2, Adam3, Ace and Pgap1), all of which result in male sterility. The sperm from these animals are known to have defective zona-binding ability and at the same time lose oviduct-migrating ability. Concerning spermzona binding, the widely accepted involvement of sugar moiety on zona pellucida 3 (ZP3) is indicated to be dispensable by gene disruption experiments. Thus, the landscape of the mechanism of fertilization is revolving considerably. In the sperm-egg fusion process, CD9 on egg and IZUMO1 on sperm have emerged as essential factors. This review focuses on the mechanism of fertilization elucidated by gene-manipulated animals.

Asian Journal of Andrology (2011) 13, 81-87; doi:10.1038/aja.2010.70; published online 8 November 2010

Keywords: egg; fusion; gene-manipulation; interaction; IZUMO1; sperm; zona pellucida

\section{INTRODUCTION}

Fertilization is the phenomenon in which sperm and egg find each other, interact and fuse. This phenomenon is essential for all plants and animals which engage in sexual reproduction. Many experiments have been performed, and papers published, using a vast number of phyla. Despite the biological importance of fertilization, the molecular mechanism of fertilization remains unknown. For example, in mammals, almost all the proteins reported to be important in sperm-egg interaction and fusion turned out to be not essentially required in fertilization under the light of gene disruption experiments ${ }^{1-5}$ (Figure 1). The gene knockout experiments have negated the old scheme of fertilization mechanism, but at the same time, this technique has serendipitously made us aware of the existence of essential genes.

A tetraspanin family CD9 which is expressed ubiquitously in the body was disrupted to find the effect on immune systems. The disruption was performed in three different laboratories at the same time and all three laboratories found that both the Cd9-disrupted male and the female mice were healthy. However, surprisingly, the Cd9-null females were sterile. Somehow, the ubiquitously-expressed CD9 was not essential in almost all the body parts, but was essential for egg to fuse with sperm. ${ }^{6-8}$ The role of CD9 in fertilization might not have been found for many years if the gene disruption technique not been applied.

This review focuses on the studies on fertilization using genemanipulated animals and describes the history of various candidates before and after the gene disruption experiments. Due to limitations on length, it was not possible to mention all the factors examined by gene-disrupted mouse lines. In this review, we aimed to provide a brief outline of the disappearance of the old scheme and an introduction to the totally new scheme which is emerging.

\section{CANDIDATE PROTEINS FOR SPERM-EGG INTERACTION Sperm-zona binding}

There have been many papers indicating the involvement of acrosin on sperm-penetrating zona pellucida (ZP). Surprisingly, however, when Acrosin-knockout mice were produced, the sperm from the mutant mice fertilized eggs without difficulty. ${ }^{1}$ This was just a prelude; all the so-called 'important' factors $(\beta$-1,4-galactosyltransferase, milk fat globule epidermal growth factor 8 , zonadhesin, sperm adhesion molecule 1 , etc.) have been demonstrated not to be essential in genedisruption experiments. ${ }^{9-11}$

\section{Sperm-egg fusion}

Fertilin. Until now, many monoclonal antibodies against sperm antigens were produced to elucidate the molecular mechanism of fertilization. ${ }^{12}$ Among those, $\mathrm{PH}-30$ was reported to inhibit sperm-egg fusion in in vitro fertilization in guinea pig. The antigen recognized by $\mathrm{PH}-30$ was identified as fertilin that is composed of two glycosylated transmembrane subunits, fertilin- $\alpha$ (ADAM1B) and fertilin- $\beta$ (ADAM2). $\mathrm{ADAM} 1 \mathrm{~B}$ and ADAM2 make a heterodimer by non-covalent binding. ${ }^{13}$ ADAM1B is conserved among broad species, albeit it is a pseudogene in human. ADAM is named after a disintegrin and metalloproteinase and forms family proteins consisting of multiple 


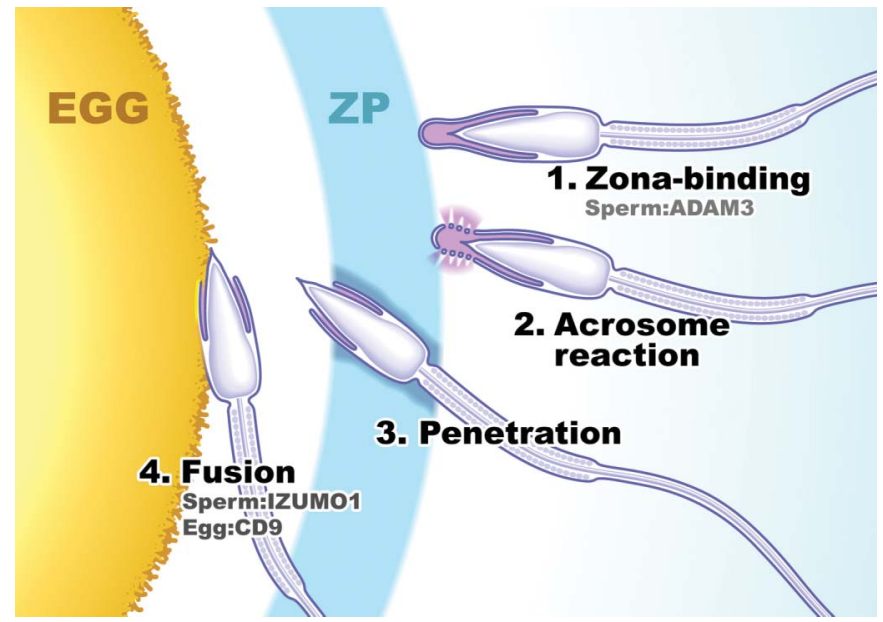

Figure 1 Mechanisms of sperm-egg interaction emerging from gene-manipulated animals. Some factors were found to be 'essential' after gene disruption. After being judged by gene disruption, ADAM3, IZUMO1 and CD9 are concluded to be indispensable factors in zona-binding on sperm, gamete fusion on sperm and on egg, respectively. As a whole, the explanation of sperm-egg interaction requires significant modification from the gene manipulation point of view. ZP consists of ZP1, ZP2 and ZP3 in mouse. Recently, it has been proved that spermegg recognition depends on the cleavage status of ZP2 by gene-manipulated mice. ADAM, a disintegrin and metalloprotease; ZP, zona pellucida.

domains: the prodomain, metalloprotease, disintegrin, cysteine-rich, epidermal growth factor-like, transmembrane and cytoplasmic tail domains. ADAM family proteins are fascinating proteins with important roles in cell adhesion, migration, proteolysis and signaling. ${ }^{14}$ ADAM family proteins in human were reported up to number ADAM39 and are still expanding. In sperm from mouse testis, fertilin (ADAM1B/ADAM2) is distributed on the plasma membrane over the entire sperm head but is found only on the posterior head once sperm have passed through the epididymis. Moreover, during the transit from the testis to the epididymis, ADAM1B and ADAM2 are both proteolytically cleaved between the metalloprotease and disintegrin domains. Thus, in mature fertilization-competent sperm, the $\mathrm{N}$ terminal of each fertilin subunit is the disintegrin domain. ${ }^{15}$ Mouse ADAM2 has a peptide sequence similar to integrin-binding Arg-GlyAsp domain. It was reported that when the recombinant protein of disintegrin domain added in in vitro fertilization assay, sperm-egg adhesion and fusion were inhibited. ${ }^{16}$ Since the extracellular domain of ADAM1B contains a hydrophobic region that resembles the fusogenic region of viral fusion proteins, it was assumed that fertilin binds to an integrin ( $\alpha \mathrm{V} \beta 3$ or $\alpha 6 \beta 1$ in mouse eggs) and thereby helps the sperm adhere to the surface of egg, which is a prerequisite for, and leads to, membrane fusion. ${ }^{17}$ One of the ADAM proteins, meltrin- $\alpha$ (ADAM12), is reported to be involved in the formation of multinucleated myotubes. ${ }^{18}$ These circumstantial data convinced many researchers to consider the fertilin as a genuine fusogenic factor in gamete fusion. If this is the case, the sperm without fertilin must fail to fuse with eggs. When fertilin was removed from sperm by eliminating one of the heterodimer genes Adam2, the male mice became infertile as expected, except that the disabled sperm function was largely a zona-binding ability rather than a fusing ability. ${ }^{19}$ Moreover, the removal of fertilin by disrupting Adam $1 b$ gene, the sperm can fertilize eggs without fertilin. ${ }^{20}$ Why do these two different fertilin knockout mouse lines show a completely a different outcome? It is now understood that when the Adam 2 gene was deleted, a testicular type of fertilin (ADAM1A/ADAM2) was disrupted together with fertilin
(ADAM1B/ADAM2). Therefore, the apparent phenotype of ADAM2 was not directly derived from the disappearance of fertilin from sperm, but from the impaired formation of testicular type fertilin. ${ }^{19,20}$

Thus, the surprising outcome of gene disruption experiments is that fertilin is not essential for sperm-fertilizing ability despite considerable circumstantial evidence indicating that fertilin is the fusion protein.

Cyritestin (ADAM3). ADAM3 is a $110-\mathrm{kDa}$ protein in testis but is found to be a $42-\mathrm{kDa}$ protein in epididymis similar to the case of ADAM1B and ADAM2. ${ }^{21}$ An eight-residue peptide from the ADAM3 disintegrin loop sequence inhibits sperm-egg adhesion and fusion ( 80 and $90 \%$ of inhibition in adhesion and fusion, respectively). Therefore, ADAM3 was thought to be implicated in sperm-egg binding and fusion ${ }^{22}$. Adam $3^{-1-}$ sperm are drastically deficient in adhesion to the egg ZP ( $0.3 \%$ of wild-type) and to the egg plasma membrane ( $9 \%$ of wild-type) in in vitro fertilization assays. However, the gene disruption experiments indicated that ADAM3 is not essential for fusion (fertilization index remained the same as in the wild-type). ${ }^{23,24}$

CD46. Human CD46 is a ubiquitously-expressed protein known to protect cells from complement attack. Anderson et al. provide evidence that regulated generation of complement C3 fragments by acrosomal enzymes and the binding of these fragments by CD46 on sperm and complement receptor 1 on eggs may be an initial step in gamete interaction, leading to membrane fusion. ${ }^{25}$ In fact, several anti-human CD46 monoclonal antibodies effectively inhibit fertilization in in vitro fertilization. ${ }^{26}$ Interestingly, mouse CD46 was found only in testis and the protein was found on the inner acrosomal membrane of sperm. ${ }^{27}$ The fact that CD46 is expressed only in testis in various mammalian species indicates the importance of CD46 in reproduction and encouraged us to make a Cd46-disrupted mouse line. Therefore, we produced mice carrying a null mutation in the $C d 46$ gene. We found no difference in the fertilizing ability of sperm from $C d 46$-null mice in in vivo and in vitro systems. The only difference we discovered was the increase in spontaneous acrosome reaction in sperm from Cd46-null mice compared to that of the wild-type sperm. Differing from our expectation, without $C d 46$, the mice were healthy and were fertile in both sexes. $^{27}$

Cysteine-rich secretory protein (CRISP). CRISPs have molecular weights of about $20-30 \mathrm{kDa}$ and are characterized by the presence of 16 conserved cysteine residues, 10 of which are clustered in the Cterminal domain of the molecule. CRISP1 and CRISP 4 are enriched in the epididymis, CRISP2 is exclusively in developing spermatids in the testes, and CRISP3 is in wider tissue distribution than the other CRISPs. ${ }^{28,29}$ When recombinant mouse CRISP1 and CRISP2 were added to eggs, they specifically bound to the fusogenic area of mouse eggs. The antibodies against these proteins significantly inhibit the fertilization ratio. ${ }^{30,31}$ Crisp1-disrupted mouse line was produced and it was found that male and female Crisp1-null mice exhibited no differences in fertilizing ability compared to wild-type animals in vivo, even though the sperm from Crisp1-disrupted mice underwent lower tyrosine phosphorylation of capacitation and reduced ability to fertilize with egg in vitro. ${ }^{32}$ It is clear that CRISP1 is dispensable for fertilization; ${ }^{32}$ however, as for the other CRISP proteins, we must wait for the production of gene-disrupted mouse lines.

MN9 antigen (equatorin). MN9 antigen/equatorin is an acrosomal protein found in various mammalian sperm, including human. It is 
reported that equatorin translocates to the plasma membrane covering the equatorial region during the acrosome reaction. Equatorin on plasma membrane is considered to function in sperm-egg fusion, because MN9 antibody inhibits both in vitro ${ }^{33}$ and in vivo fertilization systems ${ }^{34}$ without affecting zona-penetrating ability of sperm. The equatorin gene is cloned ${ }^{35}$ and has been identified as a type 1 transmembrane protein of a $40-60 \mathrm{kDa}$ and $\mathrm{N}, \mathrm{O}$-sialoglycoprotein.

The production of an equatorin-deficient mouse line is underway (Toshimori K, 2010, per. commun.).

\section{ESSENTIAL PROTEINS FOR SPERM-EGG INTERACTION}

\section{Sperm-zona binding}

ADAM3. The first gene-disrupted mouse line that showed male infertility in spite of having a normal looking sperm is the case of Calmegin disruption reported from our laboratory. ${ }^{36}$ Subsequently, five more genes were reported to cause male infertility (Adam1a, Adam2, Adam3, Ace and Pgap1). Interestingly, sperm from all six different gene-disrupted mouse lines are reported to have defects in zona-binding ability and oviduct-migrating ability. ${ }^{19,23,24,36-39}$ This strongly indicates the involvement of a common factor in sperm migration into oviduct and zona-binding ability. As far as examined, all of these gene knockout mouse lines are reported to have defects in presenting ADAM3 on their surface except Pgap1. In Pgap1 knockout mouse lines, the amount of ADAM3 on sperm was shown to be normal, but there is a chance that microdistribution of ADAM3 is affected by the elimination of PGAP1. Or else, the result of Pgap1 disruption indicates that there is an essential factor for sperm-zona binding other than ADAM3. If not ADAM3, it is highly possible that the same factor is functioning in sperm migration into oviduct and in zona-binding ability because we could observe the dual phenotype in six different gene knockouts. The reason why so many gene disruptions result in the misplacement of ADAM3 on sperm is not clear. This is certainly an interesting question to investigate.

$\mathrm{ZP}$ proteins. $\mathrm{ZP}$ consists of $\mathrm{ZP} 1, \mathrm{ZP} 2$ and $\mathrm{ZP} 3$ in mouse (ZP4 is also found in human $\mathrm{ZP}$ ). When sperm are mixed with eggs in vitro, many sperm are observed to bind to the zona. However, sperm ability to bind to zona is not necessary for sperm to fertilize eggs. It is reported that the Adam 1a-disrupted mouse sperm show an impaired zona-binding ability but when the sperm are applied to the in vitro fertilization system using eggs with cumulus cells, the sperm with impaired zona-binding ability can fertilize eggs without any problem. ${ }^{38}$ Ironically, although the zona-binding ability turned out to be dispensable, the mechanism of sperm binding to zona has been studied by many researchers. Mouse ZP3 has three important O-glycosylation sites, Ser-332, and Ser-334, and the mutation into these sites was predicted to abolish the sperm-binding ability by an in vitro translation system using somatic cells. ${ }^{40}$ However, when the same experiment was performed in vivo using gene disruption and transgenic rescue with glycosylation incompetent mutant ZP3, the glycosylation in these sites were indicated to be not essential. It was also clarified that sperm-binding ability is largely regulated by the cleavage of ZP2 after fertilization. ${ }^{5}$ However, as indicated above, the zona-binding ability of sperm seems to be not a critical characteristic for sperm to fertilize eggs. $^{38}$

\section{Sperm-egg fusion}

CD9. CD9 is a ubiquitously-expressed protein and is expected to function in various parts of the body. In 2000, three independent laboratories serendipitously and simultaneously found that a tetraspanin family CD9 on eggs was essential for eggs to fuse with sperm. ${ }^{6-8}$ In in vitro fertilization assays, $C d 9^{-1-}$ eggs failed to fuse with sperm. Therefore, the eggs remain unfertilized and many sperm continuously penetrate the zona and result in the accumulation of unfused sperm in the perivitelline space. This defect is limited to the fusion process because the infertility of $C d 9^{-/-}$eggs can be rescued by intracytoplasmic sperm injection. ${ }^{6}$ Runge et al. ${ }^{41}$ found that $C d 9^{-1-}$ eggs have an altered length, thickness and density of their microvilli by electron microscopy, suggesting that microvilli may participate in sperm-egg fusion. CD9 was the first fusion-related protein proved to be essential in the gene-manipulated animals.

Glycosylphosphatidylinositol (GPI)-anchored protein. Lipid microdomains called rafts are considered to provide specific fields on cells to facilitate many cellular processes such as signal transduction, membrane trafficking, cytoskeleton organization and pathogen entry. GPIanchored proteins are one of the factors enriched in rafts. Coonrod et al. reported that treatment of eggs with PI-PLC significantly reduced sperm-egg binding and fusion. ${ }^{42}$ When the GPI-anchoring process was demolished by egg-specific disruption of Pig- $a$ gene using ZP3 promoter-driven Cre and loxP system, the female mice became infertile due to severely impaired fusing ability with sperm. ${ }^{43}$ There are some indications of association of CD9 with GPI-anchored proteins, ${ }^{44}$ but there is another report that tetraspanin web is distinct from raft microdomains. ${ }^{45}$ Since both CD9 and GPI-anchored proteins are found on the egg surface, it would be interesting to know if there is an associated function between the CD9 and GPI-anchored proteins for fusion.

IZUMO1. We produced anti-mouse sperm monoclonal antibody OBF13 that inhibits the fusion process both in vitro and in vivo. ${ }^{46,47}$ The antigen recognized by OBF13 was not identified for many years. However, it was recently identified by two-dimensional gel electrophoresis and subsequent immunoblotting and liquid chromatography-tandem mass spectrometry analysis. We named the antigen 'Izumo' after a Japanese shrine dedicated to marriage. The gene encodes a novel immunoglobulin superfamily type I membrane protein with one extracellular Ig domain. Recently, according to Ellerman et al., ${ }^{48}$ IZUMO proteins consist of four family proteins (IZUMO1 to IZUMO4). The N-terminal domain between signal peptides and Ig domain showed a significant homology to each other and was termed 'Izumo domain'.

Acrosome-reacted sperm can be classified into three major groups by their IZUMO1-staining pattern: acrosomal cap, equatorial and whole-head (Figure 2, a2-a4). This indicates that during the acrosome reaction, IZUMO1 relocates from the anterior head of the sperm to the site(s) where fusion will take place. Since it is said that sperm launch fusion to egg at the equatorial segment, either equatorial or wholehead type IZUMO1 (Figure 2, a3 or a4) can contribute to sperm-egg fusion.

However, the question of whether or not IZUMO1 functions in fertilization could not be answered conclusive until the Izumo1deficient mice were generated by homologous recombination. After producing Izumol $^{-1-}$ mutant mice, we found they were healthy and showed no overt developmental abnormalities. As we expected, Izumo1 $^{-1-}$ males became sterile despite normal mating behavior and ejaculated to form normal vaginal plugs. Moreover, the sperm penetrated the ZP without any problem but failed to fuse with eggs. This caused an accumulation of sperm in the perivitelline space of the eggs $^{49}$ (Figure 2b). 



Figure 2 Gamete fusion-related factor IZUMO1. (a) IZUMO1 is an acrosomal membrane protein that is not exposed before the completion of an acrosome reaction (1). Acrosome-reacted sperm can be classified into three major groups by their IZUMO1-staining pattern: acrosomal cap (2), equatorial (3) and wholehead (4). (b) Accumulation of many sperm in the perivitelline space of the eggs recovered from the females mated with Izumo $1^{-1-}$ males. Sperm in the perivitelline space were labeled with acrosome-reacted sperm-specific monoclonal antibody MN9.

Why did Izumo1 ${ }^{-1-}$ sperm fail to fuse with eggs? The acrosome reaction is a prerequisite for sperm to fuse with eggs. To help answer this, we examined the acrosomal status of Izumol $^{-1-}$ sperm. In order to verify the acrosome reaction, we stained the sperm with MN9 monoclonal antibody which immunostains only to the equatorial segment of 'acrosome-reacted' sperm ${ }^{33}$ (Figure 2b). As shown in the Figure $2 \mathrm{~b}$, the Izumo1 ${ }^{-1-}$ sperm was clearly stained with MN9. This indicated the Izumo1 ${ }^{-1-}$ sperm had undergone the acrosome reaction but failed to fuse with eggs.

We further examined whether the defect of Izumol $^{-1-}$ sperm is limited to their fusing ability with eggs or whether it extends to later developmental stages. To address this question, we injected Izumo1 ${ }^{-1-}$ sperm directly into the cytoplasm of wild-type eggs and observed the ability of later development. Eggs injected with Izumo1 ${ }^{-/-}$sperm were successfully activated and the eggs implanted normally. The embryos developed to term in a normal ratio. ${ }^{49}$

\section{CHARACTERIZATION OF IZUM01 PROTEIN}

The structure of IZUMO1

As mentioned above, IZUMO1 has an Ig domain with 145 residues of $\mathrm{N}$-terminal IZUMO domain. Electrophoresis under mildly denaturing conditions, followed by western blot analysis, showed that IZUMO1 and IZUMO3 formed complexes with other protein(s) on sperm. Studies using recombinant IZUMO1 constructs suggested the IZUMO1 domain possesses the ability to form dimers. IZUMO1 might be involved in organizing or stabilizing a multiprotein complex essential for the function of the membrane fusion machinery. ${ }^{48}$

IZUMO1 possess a well-conserved $\mathrm{N}$-glycosylation site in the middle of an Ig loop among species. This site must be actually glycosylated because if we incubated mouse IZUMO1 from sperm with $\mathrm{N}$-glycosidase, the molecular weight of IZUMO1 decreased to $50 \mathrm{kDa}$ from its original $56 \mathrm{kDa}$. Since glycan composition is known to be involved in many molecular interaction mechanisms, ${ }^{50}$ we tried to examine the role of $\mathrm{N}$-glycan on IZUMO1. In order to answer this question, we produced mouse lines expressing mutated IZUMO1 in which the one hundred and eighty-third putative $\mathrm{N}$-glycosylation site aspargine was substituted to glutamine by site-directed mutagenesis under the testisspecific Calmegin promoter with rabbit $\beta$-globin polyadenylation signal. After we established N183Q-IZUMO1 males, we crossed these transgenic mouse lines with Izumol $^{-1-}$ mice and produced a mouse lines which have sperm with no $N$-glycosylation site in IZUMO1. Although the litter sizes were smaller compared to the wild-type IZUMO1, the N183Q-IZUMO1 rescued the infertile phenotype back to a fertile one. The efficiency was low, but sperm from N183QIZUMO1 could fuse with eggs (Figure $3 \mathrm{a}$ ). We extracted proteins from testis and sperm from the N183Q-IZUMO1 male mice and analyzed IZUMO1 by western blot analysis. The N183Q-IZUMO1 from testes was migrated to a $50-\mathrm{kDa}$ band area due to the lack of $\mathrm{N}$-linked glycan. However, N183Q-IZUMO1 from sperm, a severe fragmentation was observed which is not observed in wild-type IZUMO1. The major fragmented bands were observed in the $\sim 30$ - and $\sim 35-\mathrm{kDa}$ areas (Figure 3b). Although N183Q-IZUMO1 could rescue the infertile phenotype, the amount of intact N183Q-IZUMO1 present on sperm was significantly small compared to that of wild-type IZUMO1 in spite of an abundance of N183Q-IZUMO1 in testis. ${ }^{51}$ This indicates that glycosylation is not essential for the function of IZUMO1, but has a role in protecting it from fragmentation in cauda epididymis.

\section{IZUMO1-interacting protein}

Since IZUMO1 has no 'fusogenic' peptide or 'SNARE'-like structure in it, we considered the possibility that IZUMO1 might be one of the components forming fusogenic machinery on sperm. In order to search for IZUMO1-interacting proteins, we made a transgenic mouse line producing IZUMO1-His on sperm and introduced it to an Izumo1 $1^{-1-}$ background. This allowed us to immunoprecipitate IZUMO1 using anti-His antibody. The IZUMO1-interacting protein was purified from acrosome-intact sperm lysate using anti-His microbeads. We could find a specific $80-\mathrm{kDa}$ band by silver staining in the purified fraction. After liquid chromatography-tandem mass spectrometry analysis, the protein was identified as ACE3 (angiotensin I-converting enzyme 3) (Figure 4a). ${ }^{52,53}$

The immunofluorescent staining revealed that the ACE3 in fresh sperm localizes in the acrosomal cap area similar to SP56 and ACROSIN. ${ }^{54,55}$ Although the ACE3 was detected in the acrosomal cap area colocalizing with IZUMO1 before acrosome reaction, it disappeared from acrosome-reacted sperm while IZUMO1 remained (Figure 4b).

As mentioned earlier, the real function of proteins on sperm cannot be judged unless the corresponding gene is genetically modified in the mouse. We therefore generated Ace3-deficient mice by homologous recombination. Differing from our expectation, the Ace $3^{-1-}$ mice showed signs of infertility both in males and in females. We analyzed the fertilizing ability of $A c e 3^{-1-}$ sperm in the in vitro fertilization systems. Again, the $A c e 3^{-1-}$ sperm showed normal fertilizing ability in our in vitro fertilization system using both cumulus-intact and cumulus-free eggs. These results suggest that ACE3 do bind to IZUMO1, but this characteristic nature is not required for sperm to fertilize eggs. ${ }^{53}$

\section{FACTORS THAT AFFECT THE LOCALIZATION OF IZUMO1}

\section{Sperm equatorial segment protein 1 (SPESP1)}

It is well accepted that sperm-egg fusion starts at the equatorial segment of sperm head. IZUMO1 can spread over the entire head covering the equatorial segment, but this does not explain the equatorial segment-restricted fusion. ${ }^{49}$ There are various sperm proteins known to be distributed only in the equatorial segment. There are chances that 

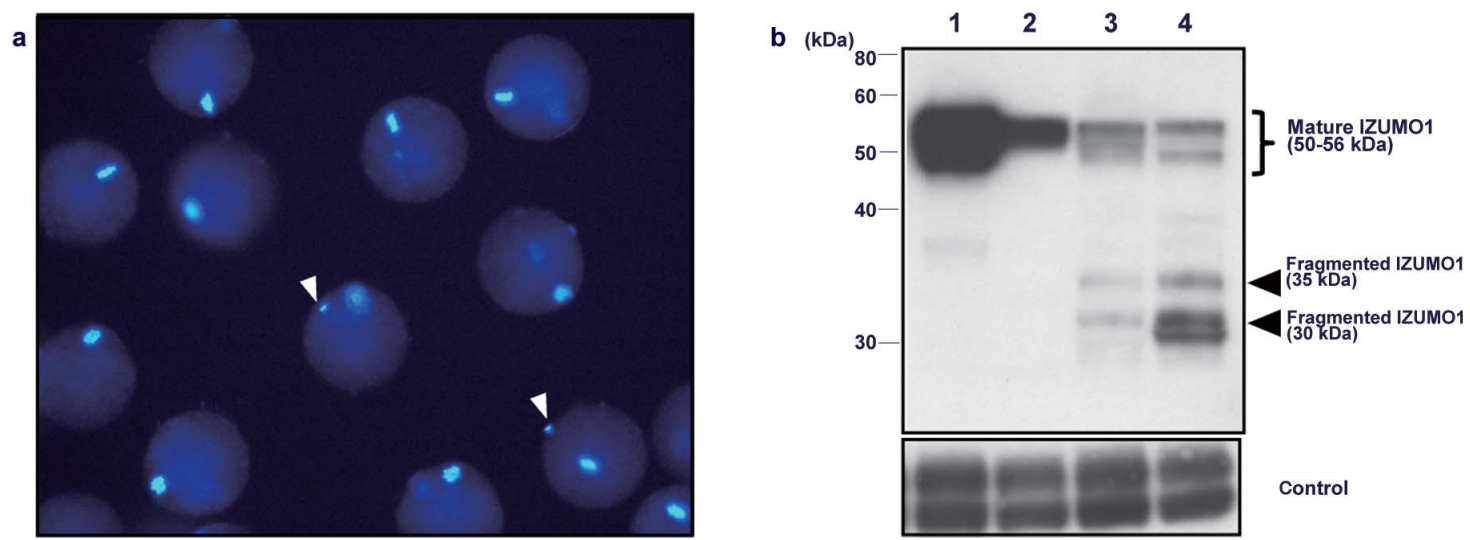

Figure $3 \mathrm{~N}$-linked glycan of IZUMO1 is not essential for fusion. (a) Comparison of the fusing ability of wild-type and N183Q-IZUMO1 sperm. The arrowheads indicate fused sperm. N183Q-IZUMO1 sperm are able to fuse with eggs, albeit in low yield (fusion index: 0.05 fused sperm/egg). (b) Fragmentation of N183Q-IZUMO1 protein in cauda epididymal sperm. N183Q-IZUMO1 is fragmented by protease in cauda epididymal sperm (filled arrowheads). Lane 1, Wild-type; Lane 2, Izumo1 ${ }^{-1-}$ Izumo1-Tg; Lane 3, Izumo1 ${ }^{-1-}$ Izumo1N183Q-Tg\#1; Lane 4, Izumo1 ${ }^{-1-}$ Izumo1N183Q-Tg\#2.
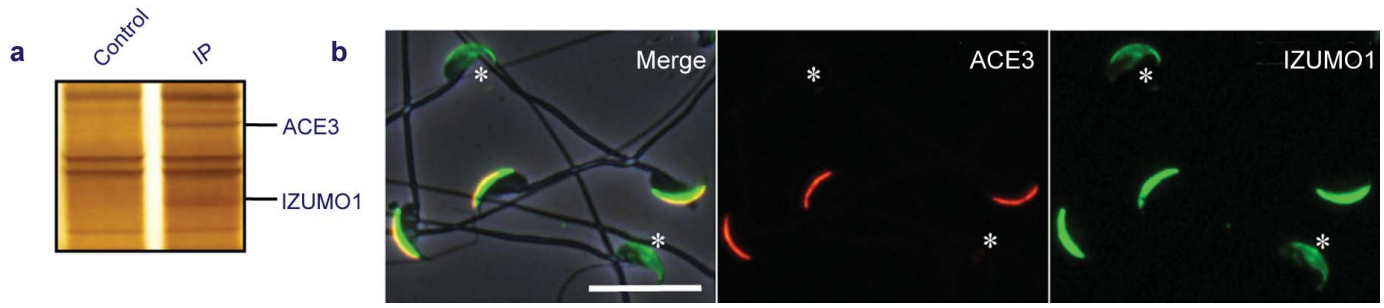

Figure 4 Identification of IZUMO1-interacting proteins. (a) The purified IZUMO1 protein complex was separated by SDS-PAGE and then silver stained. Two specific 80- and 56-kDa bands appeared corresponding to ACE3 and IZUMO1, respectively. (b) Subcellular localization of ACE3 protein in mature sperm was examined in incubated cauda epididymal sperm. They were stained with anti-ACE3 (red) and anti-IZUMO1 (green) antibodies. The anti-ACE3 antibody stained acrosome-intact sperm head, but did not react to acrosome-reacted sperm (asterisk). Scale bar $=20 \mu \mathrm{m}$. ACE3, angiotensin I-converting enzyme 3; PAGE, polyacrylamide gel electrophoresis.
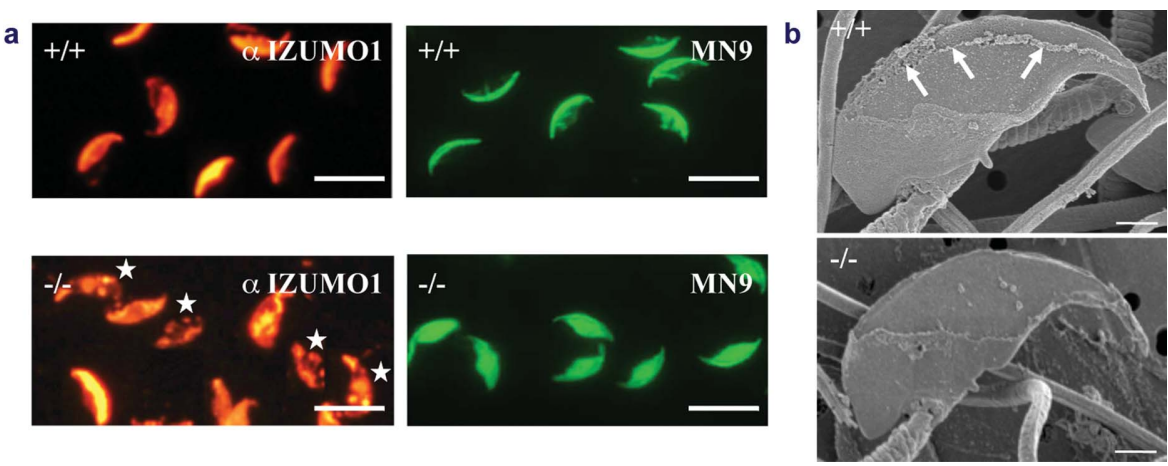

Figure 5 SPESP1. (a) Many of the Spesp1-disrupted sperm showed abnormal spreading of IZUMO1 after acrosome reaction (indicated by asterisks in the figure). The localization pattern of MN9 antigen was also significantly affected by the disruption of Spesp1. Scale bars $=10 \mu \mathrm{m}$. (b) Scanning electron microscopy of Spesp1deficient and wild-type sperm. In wild-type sperm, the plasma membrane in the acrosome cap area disappeared down to the border of the equatorial segment after acrosome reaction. However, in Spesp1-deficient sperm, the plasma membrane disappeared from a wider area. As a result, the inner acrosomal membrane was exposed in most of the equatorial segment area (indicated by arrowheads). Scale bars $=1 \mu \mathrm{m}$. SPESP1, sperm equatorial segment protein 1.

one of these proteins is functioning in sperm-egg fusion. ${ }^{35,56-58}$ SPESP1 was one of the candidates functioning for fusion, because anti-SPESP1 antibody was known to inhibit human sperm from fusing with hamster eggs as well as inhibiting sperm-egg fusion in mouse. ${ }^{59}$

A mouse line lacking Spesp1 was produced by homologous recombination and the fertilizing ability of male mice was examined. ${ }^{60}$ The decreased fertilizing ability was found not only in Spesp $1^{-1-}$ sperm but also in Spesp1 $1^{+/-}$sperm. Despite the normal number of ejaculated sperm and normal motility, Spesp1-disrupted mouse had a decreased number of pups compared to wild-type mice. When we examined the localization of IZUMO1 in Spesp1-disrupted sperm, we found IZUMO1 localized in a broader area in a more spotty manner. The aberrant distribution of membrane proteins was more prominent in the case of MN9 antigen. In wild-type sperm, MN9 antigen did not spread to the equatorial segment before acrosome reaction, but when Spesp1 was disrupted, MN9 antigen was not restricted to the acroso- 
mal cap area, but to the equatorial segment even before the acrosome reaction (Figure 5a). When we observed the sperm using a scanning electron microscope, we found a complete removal of the equatorial segment membrane from all of the Spesp $1^{-/-}$sperm (Figure $5 \mathrm{~b}$ ). This could be an artifact during the preparation of the sperm sample, but it is certain that the equatorial segment membrane in Spesp $1^{-1-}$ sperm becomes very fragile compared to that of wild-type sperm and affects the distribution of IZUMO1. ${ }^{60}$

\section{TSSK6}

TSSK6 is a member of the testis-specific serine kinase and is expressed postmeiotically in male germ cells. The Tssk6-null mice are infertile producing mostly morphologically deformed sperm. However, the morphology is not the only cause for infertility. Thirteen percent of the sperm from the mice showed a normal morphology, but failed to fertilize eggs in vitro and failed to fuse with zona-free eggs. Interestingly, in $T s s k 6^{-1-}$ sperm, the relocalization of IZUMO1 after acrosome reaction is impaired. It is assumed that polymerization of actin is required for this relocalization, because an inhibitor for actin polymerization blocks the relocalization of IZUMO1. ${ }^{61}$ However, in Tssk $\sigma^{-1-}$ sperm, polymerized actins disappeared from the midpiece and the posterior head of sperm. Thus, TSSK6 may regulate the localization of IZUMO1 by regulating the polymerization of actin after acrosome reaction. ${ }^{61}$

\section{CONCLUSION}

Recent observations of infertile phenotypes derived from various gene-disrupted mouse lines have rendered the old scheme for the mechanism of fertilization obsolete. Many essential genes were required to express ADAM3 properly on the sperm surface, as shown by gene disruption experiments. ${ }^{19,23,24,36-38}$ This indicates that ADAM3 is the key molecule in fertilization, but this scheme is not applicable in human because Adam3 is a pseudogene in human. ${ }^{62}$ Thus, although a partial mechanism has been clarified, a new (or modified) outline for the mechanism of fertilization must await the results of further gene knockout experiments. Concerning fusion mechanism, it might be important to broaden our focus to wider areas of the cell-cell fusion process such as the formation of myotubes, placenta, multinucleated osteoclasts and macrophages, for example. In any case, the clarification of the molecular mechanism of fertilization will benefit clinical treatment of infertility and will underpin the potential development of novel contraceptive strategies in the future.

\section{COMPETING FINANCIAL INTERESTS}

The authors declare no competing financial interests.

\section{ACKNOWLEDGMENTS}

This work was supported by grants from the Ministry of Education, Culture, Sports, Science, and Technology of Japan.

1 Baba T, Azuma S, Kashiwabara S, Toyoda Y. Sperm from mice carrying a targeted mutation of the acrosin gene can penetrate the oocyte zona pellucida and effect fertilization. J Biol Chem 1994; 269: 31845-9.

$2 \mathrm{Lu}$ Q, Shur BD. Sperm from beta 1,4-galactosyltransferase-null mice are refractory to ZP3-induced acrosome reactions and penetrate the zona pellucida poorly. Development 1997; 124: 4121-31.

3 He ZY, Brakebusch C, Fassler R, Kreidberg JA, Primakoff P et al. None of the integrins known to be present on the mouse egg or to be ADAM receptors are essential for spermegg binding and fusion. Dev Biol 2003; 254: 226-37.

4 Ikawa M, Inoue N, Benham AM, Okabe M. Fertilization: a sperm's journey to and interaction with the oocyte. J Clin Invest 2010; 120: 984-94.
5 Gahlay G, Gauthier L, Baibakov B, Epifano O, Dean J. Gamete recognition in mice depends on the cleavage status of an egg's zona pellucida protein. Science 2010; 329: 216-9.

6 Miyado K, Yamada G, Yamada S, Hasuwa H, Nakamura Y et al. Requirement of CD9 on the egg plasma membrane for fertilization. Science 2000; 287: 321-4.

7 Le Naour F, Rubinstein E, Jasmin C, Prenant M, Boucheix C. Severely reduced female fertility in CD9-deficient mice. Science 2000; 287: 319-21.

8 Kaji K, Oda S, Shikano T, Ohnuki T, Uematsu Y et al. The gamete fusion process is defective in eggs of Cd9-deficient mice. Nat Genet 2000; 24: 279-82.

9 Baba D, Kashiwabara S, Honda A, Yamagata K, Wu Q et al. Mouse sperm lacking cell surface hyaluronidase $\mathrm{PH}-2 \mathrm{O}$ can pass through the layer of cumulus cells and fertilize the egg. J Biol Chem 2002; 277: 30310-4.

10 Ensslin MA, Shur BD. Identification of mouse sperm SED1, a bimotif EGF repeat and discoidin-domain protein involved in sperm-egg binding. Cell 2003; 114: 405-17.

11 Tardif S, Wilson MD, Wagner R, Hunt P, Gertsenstein M et al. Zonadhesin is essential for species specificity of sperm adhesion to the egg's zona pellucida. $J$ Biol Chem 2010; 285: 24863-70.

12 Yanagimachi R. Mammalian fertilization. The Physioloy of Reproduction. 2nd ed. New York: Raven Press; 1994. p189-317

13 Blobel CP, Wolfsberg TG, Turck CW, Myles DG, Primakoff $\mathrm{P}$ et al. A potential fusion peptide and an integrin ligand domain in a protein active in sperm-egg fusion. Nature 1992; 356: 248-52.

14 Reiss K, Saftig P. The 'a disintegrin and metalloprotease' (ADAM) family of sheddases: physiological and cellular functions. Semin Cell Dev Biol 2009; 20: 126-37.

15 Hunnicutt GR, Koppel DE, Myles DG. Analysis of the process of localization of fertilin to the sperm posterior head plasma membrane domain during sperm maturation in the epididymis. Dev Biol 1997; 191: 146-59.

16 Myles DG, Kimmel LH, Blobel CP, White JM, Primakoff P. Identification of a binding site in the disintegrin domain of fertilin required for sperm-egg fusion. Proc Nat/ Acad Sci USA 1994; 91: 4195-8.

17 Almeida EA, Huovila AP, Sutherland AE, Stephens LE, Calarco PG et al. Mouse egg integrin alpha 6 beta 1 functions as a sperm receptor. Cell 1995; 81: 1095-104.

18 Yagami-Hiromasa T, Sato T, Kurisaki T, Kamijo K, Nabeshima $\mathrm{Y}$ et al. A metalloprotease-disintegrin participating in myoblast fusion. Nature 1995; 377 : 652-6.

19 Cho C, Bunch DO, Faure JE, Goulding EH, Eddy EM et al. Fertilization defects in sperm from mice lacking fertilin beta. Science 1998; 281: 1857-9.

20 Kim E, Yamashita M, Nakanishi T, Park KE, Kimura M et al. Mouse sperm lacking ADAM1b/ADAM2 fertilin can fuse with the egg plasma membrane and effect fertilization. J Biol Chem 2006; 281: 5634-9.

21 Nishimura H, Myles DG. Primakoff P. Identification of an ADAM2-ADAM3 complex on the surface of mouse testicular germ cells and cauda epididymal sperm. J Biol Chem 2007; 282: 17900-7.

22 Yuan R, Primakoff P, Myles DG. A role for the disintegrin domain of cyritestin, a sperm surface protein belonging to the ADAM family, in mouse sperm-egg plasma membrane adhesion and fusion. J Cell Biol 1997; 137: 105-12.

23 Shamsadin R, Adham IM, Nayernia K, Heinlein UA, Oberwinkler $\mathrm{H}$ et al. Male mice deficient for germ-cell cyritestin are infertile. Biol Reprod 1999; 61: 1445-51.

24 Nishimura H, Cho C, Branciforte DR, Myles DG, Primakoff P. Analysis of loss of adhesive function in sperm lacking cyritestin or fertilin beta. Dev Biol 2001; 233: 204-13.

25 Anderson DJ, Abbott AF, Jack RM. The role of complement component C3b and its receptors in sperm-oocyte interaction. Proc Natl Acad Sci USA 1993; 90: 10051-5.

26 Okabe M, Nagira M, Kawai Y, Matzno S, Mimura T et al. A human sperm antigen possibly involved in binding and/or fusion with zona-free hamster eggs. Fertil Steril 1990; 54: 1121-6.

27 Inoue N, Ikawa M, Nakanishi T, Matsumoto M, Nomura M et al. Disruption of mouse CD46 causes an accelerated spontaneous acrosome reaction in sperm. Mol Cell Biol 2003; 23: 2614-22.

28 Roberts KP, Johnston DS, Nolan MA, Wooters JL, Waxmonsky NC et al. Structure and function of epididymal protein cysteine-rich secretory protein-1. Asian J Androl 2007; 9: 508-14.

29 Cohen DJ, Busso D, Da Ros V, Ellerman DA, Maldera JA et al. Participation of cysteinerich secretory proteins (CRISP) in mammalian sperm-egg interaction. Int J Dev Biol 2008; 52: 737-42

30 Rochwerger L, Cohen DJ, Cuasnicu PS. Mammalian sperm-egg fusion: the rat egg has complementary sites for a sperm protein that mediates gamete fusion. Dev Biol 1992; 153: 83-90.

31 Busso D, Goldweic NM, Hayashi M, Kasahara M, Cuasnicu PS. Evidence for the involvement of testicular protein CRISP2 in mouse sperm-egg fusion. Biol Reprod 2007; 76: 701-8.

32 Da Ros VG, Maldera JA, Willis WD, Cohen DJ, Goulding EH et al. Impaired sperm fertilizing ability in mice lacking cysteine-rich secretory protein 1 (CRISP1). Dev Biol 2008; 320: 12-8.

33 Toshimori K, Saxena DK, Tanii I, Yoshinaga K. An MN9 antigenic molecule, equatorin, is required for successful sperm-oocyte fusion in mice. Biol Reprod 1998; 59: 22-9.

34 Yoshinaga K, Saxena DK, Oh-oka T, Tanii I, Toshimori K. Inhibition of mouse fertilization in vivo by intra-oviductal injection of an anti-equatorin monoclonal antibody. Reproduction 2001; 122: 649-55.

35 Yamatoya K, Yoshida K, Ito C, Maekawa M, Yanagida M et al. Equatorin: identification and characterization of the epitope of the MN9 antibody in the mouse. Biol Reprod 2009; 81: 889-97.

36 Ikawa M, Wada I, Kominami K, Watanabe D, Toshimori K et al. The putative chaperone calmegin is required for sperm fertility. Nature 1997; 387: 607-11. 
37 Hagaman JR, Moyer JS, Bachman ES, Sibony M, Magyar PL et al. Angiotensinconverting enzyme and male fertility. Proc Natl Acad Sci USA 1998; 95: 2552-7.

38 Nishimura H, Kim E, Nakanishi T, Baba T. Possible function of the ADAM1a/ADAM2 Fertilin complex in the appearance of ADAM3 on the sperm surface. $J$ Biol Chem 2004; 279: 34957-62.

39 Ueda Y, Yamaguchi R, Ikawa M, Okabe M, Morii E et al. PGAP1 knock-out mice show otocephaly and male infertility. J Biol Chem 2007; 282: 30373-80.

40 Chen J, Litscher ES, Wassarman PM. Inactivation of the mouse sperm receptor, mZP3, by site-directed mutagenesis of individual serine residues located at the combining site for sperm. Proc Natl Acad Sci USA 1998; 95: 6193-7.

41 Runge KE, Evans JE, He ZY, Gupta S, McDonald KL et al. Oocyte CD9 is enriched on the microvillar membrane and required for normal microvillar shape and distribution. Dev Biol 2007; 304: 317-25.

42 Coonrod SA, Naaby-Hansen S, Shetty J, Shibahara H, Chen M et al. Treatment of mouse oocytes with PI-PLC releases 70-kDa (pl 5) and 35- to 45-kDa (pl 5.5) protein clusters from the egg surface and inhibits sperm-oolemma binding and fusion. Dev Biol 1999; 207: 334-49.

43 Alfieri JA, Martin AD, Takeda J, Kondoh G, Myles DG et al. Infertility in female mice with an oocyte-specific knockout of GPI-anchored proteins. J Cell Sci 2003; 116 2149-55.

44 Claas C, Stipp CS, Hemler ME. Evaluation of prototype transmembrane 4 superfamily protein complexes and their relation to lipid rafts. J Biol Chem 2001; 276: 7974-84.

45 Espenel C, Margeat E, Dosset P, Arduise C, Le Grimellec C et al. Single-molecule analysis of $\mathrm{CD} 9$ dynamics and partitioning reveals multiple modes of interaction in the tetraspanin web. J Cell Biol 2008; 182: 765-76.

46 Okabe M, Adachi T, Takada K, Oda H, Yagasaki M et al. Capacitation-related changes in antigen distribution on mouse sperm heads and its relation to fertilization rate in vitro. J Reprod Immunol 1987; 11: 91-100.

47 Okabe M, Yagasaki M, Oda H, Matzno S, Kohama Y et al. Effect of a monoclonal antimouse sperm antibody (OBF13) on the interaction of mouse sperm with zona-free mouse and hamster eggs. J Reprod Immunol 1988; 13: 211-9.

48 Ellerman DA, Pei J, Gupta S, Snell WJ, Myles D et al. Izumo is part of a multiprotein family whose members form large complexes on mammalian sperm. Mol Reprod Dev 2009; 76: 1188-99.

49 Inoue $\mathrm{N}$, Ikawa $\mathrm{M}$, Isotani A, Okabe $\mathrm{M}$. The immunoglobulin superfamily protein Izumo is required for sperm to fuse with eggs. Nature $2005 ; 434: 234-8$.
50 Ohtsubo K, Marth JD. Glycosylation in cellular mechanisms of health and disease. Cell 2006; 126: 855-67.

51 Inoue N, Ikawa M, Okabe M. Putative sperm fusion protein IZUMO and the role of $\mathrm{N}$ glycosylation. Biochem Biophys Res Commun 2008; 377: 910-4.

52 Rella M, Elliot JL, Revett TJ, Lanfear J, Phelan A et al. Identification and characterisation of the angiotensin converting enzyme-3 (ACE3) gene: a nove mammalian homologue of ACE. BMC Genomics 2007; 8: 194.

53 Inoue N, Kasahara T, Ikawa M, Okabe M. Identification and disruption of spermspecific angiotensin converting enzyme-3 (ACE3) in mouse. PLoS One 2010; 5 e10301.

54 Ramalho-Santos J, Moreno RD, Wessel GM, Chan EK, Schatten G. Membrane trafficking machinery components associated with the mammalian acrosome during spermiogenesis. Exp Cell Res 2001; 267: 45-60.

55 Kim KS, Cha MC, Gerton GL. Mouse sperm protein sp56 is a component of the acrosomal matrix. Biol Reprod 2001; 64: 36-43.

56 Hao Z, Wolkowicz MJ, Shetty J, Klotz K, Bolling L et al. SAMP32, a testis-specific, isoantigenic sperm acrosomal membrane-associated protein. Biol Reprod 2002; 66 735-44.

57 Wolkowicz MJ, Shetty J, Westbrook A, Klotz K, Jayes F et al. Equatorial segment protein defines a discrete acrosomal subcompartment persisting throughout acrosomal biogenesis. Biol Reprod 2003; 69: 735-45.

58 Shetty J, Wolkowicz MJ, Digilio LC, Klotz KL, Jayes FL et al. SAMP14, a novel, acrosomal membrane-associated, glycosylphosphatidylinositol-anchored member of the Ly-6/urokinase-type plasminogen activator receptor superfamily with a role in sperm-egg interaction. J Biol Chem 2003; 278: 30506-15.

59 Wolkowicz MJ, Digilio L, Klotz K, Shetty J, Flickinger CJ et al. Equatorial segment protein (ESP) is a human alloantigen involved in sperm-egg binding and fusion. J Androl 2008; 29: 272-82.

60 Fujihara Y, Murakami M, Inoue N, Satouh Y, Kaseda K et al. Sperm equatorial segment protein 1, SPESP1, is required for fully fertile sperm in mouse. J Cell Sci 2010; 123: 1531-6.

61 Sosnik J, Miranda PV Spiridonov NA, Yoon SY, Fissore RA et al. Tssk6 is required for Izumo relocalization and gamete fusion in the mouse. J Cell Sci 2009; 122: 2741-9.

62 Grzmil P, Kim Y, Shamsadin R, Neesen J, Adham IM et al. Human cyritestin genes (CYRN1 and CYRN2) are non-functional. Biochem J2001; 357(Pt 2):551-6. 